\title{
Modified Eady Waves and Frontogenesis Part I: Linear Stability Analysis
}

\author{
WEN-YIH SUN \\ Department of Earth and Atmospheric Sciences \\ Purdue University, W. Lafayette, IN 47907, U.S.A. \\ (Received 5 November 1990; revised 30 December 1990)
}

\begin{abstract}
Baroclinic instability in an inviscid fluid with parabolic potential temperature profiles is investigated. Unlike the classical Eady model, there is no short wave cutoff. In addition to the longwave disturbances, which are similar to the Eady waves, shortwave disturbances can also develop in the lower atmosphere, where the stratification is weaker. The growth rate of the short waves increases with increasing stratification aloft. The results show that shortwave disturbances can penetrate into the upper stable layer. The growth rate and disturbances of those waves may be associated with an effective Burger number, which is defined as

$$
\beta \mathrm{eff}=\frac{g\left(2 h^{*}\right)^{2}}{\theta_{0} f^{2} \lambda^{2}}\left(\frac{\partial \theta}{\partial z}\right)_{h^{*}}
$$

where $h^{*}$ is the height of the maximum vertical heat flux $\left(w^{\prime} \theta^{\prime}\right)$ and $\lambda$ is the horizontal wavelength.

Numerical simulations obtained from a nonlinear mesoscale model in Part II also confirm that the short waves can develop into a surface front within a few days. Those short waves may correspond to the medium-scale disturbances observed over the AMTEX (스 Mass Transformation EXperiment) region.
\end{abstract}

\section{INTRODUCTION}

One of the most important phenomena observed during the AMTEX (슬 Mass Transformation EXperiment) was the occurrence of medium-scale disturbances over the East China Sea in winter (Nitta et al., 1973). The length scale of the medium-scale disturbances was $1000-2000 \mathrm{~km}$ in the east-west direction. The disturbances became active in a moist lower troposphere under conditions of a less stable thermal stratification, and are not associated with an upper 
tropospheric trough. The conventional baroclinic instability and symmetric instability have been applied to study the medium-scale disturbances. Because of a constant Richardson number ( $R i$ ) being used in the entire domain, the results obtained by Gambo $(1970 \mathrm{a}, \mathrm{b})$ and Tokioka $(1970,1971)$ fail to explain some important characteristics of these disturbances. Observations indicated that the stratification in the lower atmosphere was much less than in the upper atmosphere during the AMTEX. Here, the Eady (1949) model is modified by assuming that the stratification increases with height. Recently, Blumen (1979) and Nalamura (1988) also applied baroclinic instability to study the development of the mesoscale disturbances over the Atlantic Ocean.

\section{BAROCLINIC INSTABILITY}

Baroclinic instability associated with the large scale disturbances in midlatitude has been investigated by Eady (1949), Charney and Stern (1962), Stone (1966) and many others. Following Eady's pioneering work, several variations of the Eady model have been introduced. Williams (1974) documented that simple analytical solutions, in terms of hyperbolic functions, exist for Eady's instability problem, as long as the shear and static stability have the same functions with height. His results are quite limited and difficult to apply to the medium-scale disturbances due to a shortwave cutoff. Instability of a verticallyvarying geostrophic flow in an atmosphere with neutral or unstable stratification in the surface layer and stable stratification above have also been investigated by Kuo and Seitter (1985). They find both symmetric and convectional baroclinic instability in their results. Baroclinic instability of short waves has also been studied by Staley and Gall (1977) by using a four-level numerical model. Blumen (1979) used a two-layer Eady model to study the instability of short waves due to the jump of stratification at the interface. Baroclinic instability in a nongeostrophic system for a fluid, which includes a smooth transition layer between two layers of different stratification, has also been studied by Nakamura (1988). Their results confirm that the short waves become unstable if stratification in the lower atmosphere is weak. Those short waves are very sensitive to the stratification in the lower atmosphere.

Here, a constant wind shear is assumed in the $u$-component. The vertical (potential) temperature profile is described by a simple second-order polynomial function, which provides a weakly stable stratified atmosphere near the surface and a very stable layer in the upper atmosphere. This may resemble the climatic environment over the TAMEX region during winter. The reduction and iterative method developed by Kuo (1978) was used to calculate the eigen value and eigen function in this modified Eady problem. 


\section{a. Basic equations for a modified Eady model}

With the pseudo-height $z=\left(H_{s} / \kappa\right)\left(1-\left(p / p_{0}\right)^{\kappa}\right)$ (Hoskins,1971) being used as a modified vertical coordinate, the basic equations for an inviscid, compressible atmosphere are identical to William's model (1967) with Boussinesq approximation. Hence, they will not be repeated here. The initial basic (potential) temperature may be represented by a group of parabolic profiles,

$$
\theta=a z^{2}+b z+\theta_{0}+(\partial \theta / \partial y) y
$$

where $a$ and $b$ are constants, and will be discussed later. We are limited to stable stratification in the whole atmosphere where the Richardson number is greater than one to avoid symmetric instability, as discussed by Stone (1966).

The basic wind is assumed:

$$
U=\frac{V_{z}}{H}
$$

and the variation of the initial theta $\theta$ in the $y$ direction is

$$
\frac{\partial \theta}{\partial y}=-\frac{f \theta_{0}}{g} \frac{\partial U}{\partial z}=-\frac{f \theta_{0} V}{g H}=\text { constant }
$$

Following Drazin (1978), in a two dimensional flow, we can have a single nondimensional equation for perturbation pressure variables $\phi^{*}$ in a quasigeostrophic system:

$$
\left(\frac{\partial}{\partial t^{*}}+z^{*} \frac{\partial}{\partial x^{*}}\right)\left(\frac{\partial^{2} \phi^{*}}{\partial x^{* 2}}+\frac{\partial}{\partial z^{*}}\left(\frac{1}{\beta} \frac{\partial \phi^{*}}{\partial z^{*}}\right)\right)-\frac{\partial \phi^{*}}{\partial x^{*}} \frac{d(1 / \beta)}{d z^{*}}=0
$$

where the Burger number $\beta=\left(g H^{2} / \theta_{0} f^{2} L^{2}\right)(d \theta / d z)=N^{2} H^{2} / f^{2} L^{2}=R i R_{0}^{2}$, where $N^{2}=\left(g / \theta_{0}\right)(d \theta / d z)$, and $R i, R_{0}$ are Richardson number and Rossby number, respectively. The boundary conditions of (2.4) are

$$
w^{*}=\frac{1}{\beta}\left[\left(\frac{\partial}{\partial t^{*}}+z^{*} \frac{\partial}{\partial x^{*}}\right)\left(\frac{\partial \phi^{*}}{\partial z^{*}}\right)-\frac{\partial \phi^{*}}{\partial x^{*}}=0, \text { at } z^{*}=0,1\right.
$$

Eq. (2.4) corresponds to the conservation of quasi-geostrophic potential vorticity (Charney and Stern, 1962), which is defined as $q=Q+q^{t}$ with

$$
q^{\prime}=\zeta^{\prime}+f \frac{\partial}{\partial z}\left(\frac{1}{N^{2}} \frac{\partial p^{\prime}}{\partial z}\right) \text { and } \frac{\partial Q}{\partial y}=-\frac{\partial}{\partial z}\left(\frac{f^{2}}{N^{2}} \frac{\partial U}{\partial z}\right)
$$

In (2.32) and (2.34), the solution is assumed in the form of

$$
\phi^{*}=\Phi\left(z^{*}\right) \exp \left(i \alpha\left(x^{*}-c t^{*}\right)\right),
$$


we obtain a second order differential equation for $\Phi$

$$
\frac{d^{2} \Phi}{d z^{* 2}}-\frac{d \beta / d z^{*}}{\beta} \frac{d \Phi}{d z^{*}}+\left(\frac{d \beta / d z^{*}}{\beta} \frac{1}{\left(-c+z^{*}\right)}-\beta \alpha^{2}\right) \Phi=0,
$$

while boundary conditions are:

$$
\left(-c+z^{*}\right) \frac{d \Phi}{d z^{*}}=\Phi \text { at } z^{*}=0,1 .
$$

The eigenvalue problem represented. by Eqs. (2.8) and (2.9) can be solved by the reduction and iteration method (Kuo; 1978). Kuo's method has been proved quite accurate in this study (Kao, 1987).

\section{EIGEN VALUES OF THE MODIFIED EADY PROBLEM}

Here, the basic potential temperature is a function of height $(z)$ and latitude $(y)$ :

$$
\theta=a z^{2}+b z+\theta_{0}+\left(\frac{\partial \theta}{\partial y}\right) y
$$

The constants are: $\boldsymbol{a}=n \times \operatorname{del}$, where $n=1,2,3,4,5$ for cases $2 \mathrm{a}$ to $2 \mathrm{e}$, and $n=0$ for a Eady problem (indicated by $\mathrm{E}$ ); del $=0.05 \mathrm{~K} \mathrm{~km}^{-2}$; $b=2.0 \mathrm{~K} \mathrm{~km}^{-1} ; \theta_{0}=288 \mathrm{~K}$, and $\partial \theta / \partial y=-10^{-5} \mathrm{~K} \mathrm{~m}^{-1}$. In addition to these profiles, we also include another case (indicated as Es) with $a=0$, and $b=3.9 \mathrm{~K} \mathrm{~km}^{-1}$, corresponding to a Eady problem with more stable stratification.

In the stability analysis, the length scale $L$ is chosen to be $1000 \mathrm{~km}$. The wave numbers $\alpha$ tested range from 0 to 5 (according to wavelength $\lambda \geq 2 \pi L / 5=$ $1256.6 \mathrm{~km}$ ). The horizontal length of the medium-scale disturbances observed over the AMTEX region is about $1000-2000 \mathrm{~km}$, which is within the range of this study. The basic potential temperature profiles and the corresponding Burger numbers are shown in Figs. 1 and 2, respectively. The Burger numbers at $z^{*}=0.5$ of cases $2 \mathrm{a}-2 \mathrm{~b}$ are approximately bounded by the Burger numbers of cases $\mathrm{E}$ and Es, as shown in Fig. 2.

The phase speed and growth rate obtained are shown in Figs. 3 and 4 as functions of wave number a for various basic potential temperature profiles given by (3.1). It is found that in the longwave region (Mode I), the phase speed $\mathrm{cr}$ and growth rate $\left(\alpha c_{i}\right)$ decrease with increasing stratification. It is interesting to note that the growth rate of long waves (in Fig. 4) corresponds very well with the average Burger numbers for different cases shown in Fig. 2. The Burger number of Es is slightly less than that of $2 \mathrm{e}$ at $z^{*} \approx 0.5$. Hence, the maximum growth rate of Es is slightly linger than that of $2 \mathrm{e}$. Table 1 


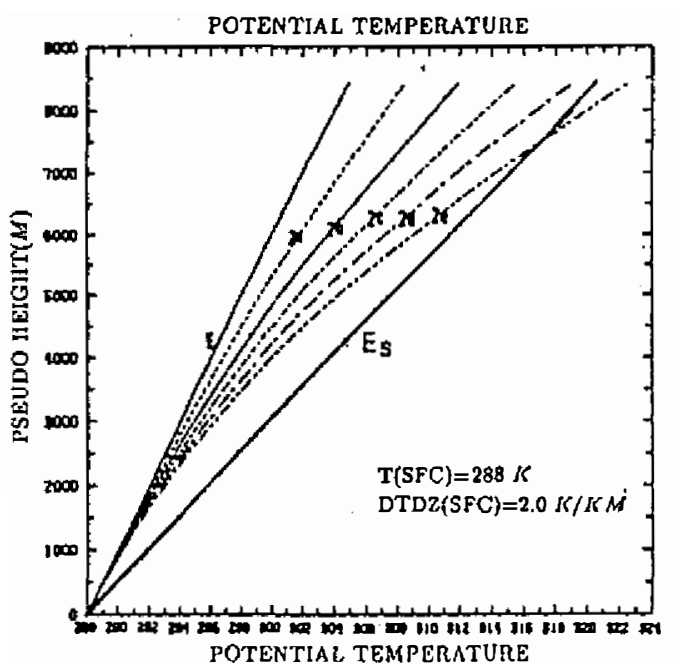

Fig. 1. The basic potential temperature profiles in the modified Eady problem.

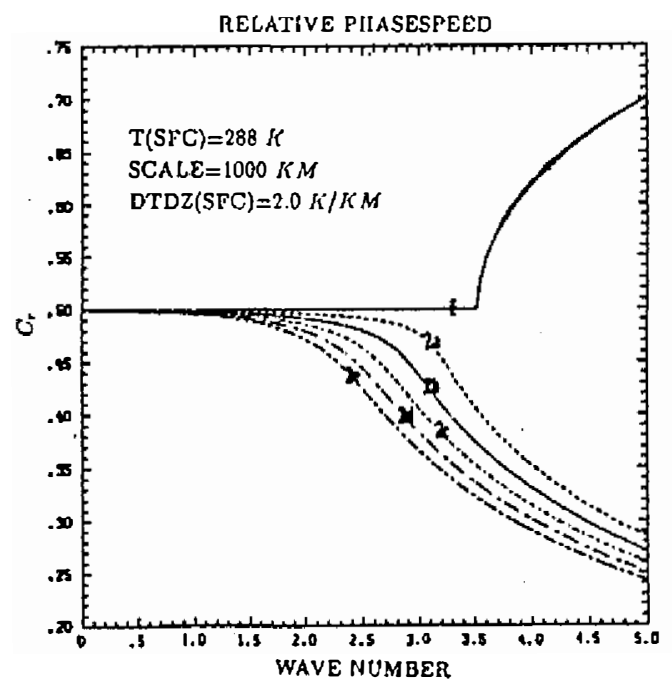

Fig. 3. Variations of the real part of eigenvalue, $c_{r}$ (relative phase speed), with wave number.

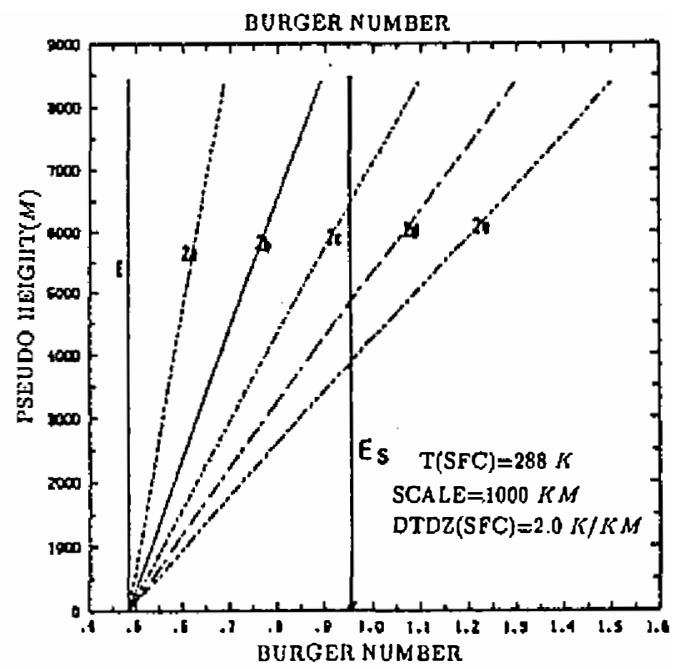

Fig. 2. The Burger number $\beta$ in conjunction with the potential temperature profiles in Fig. 1.

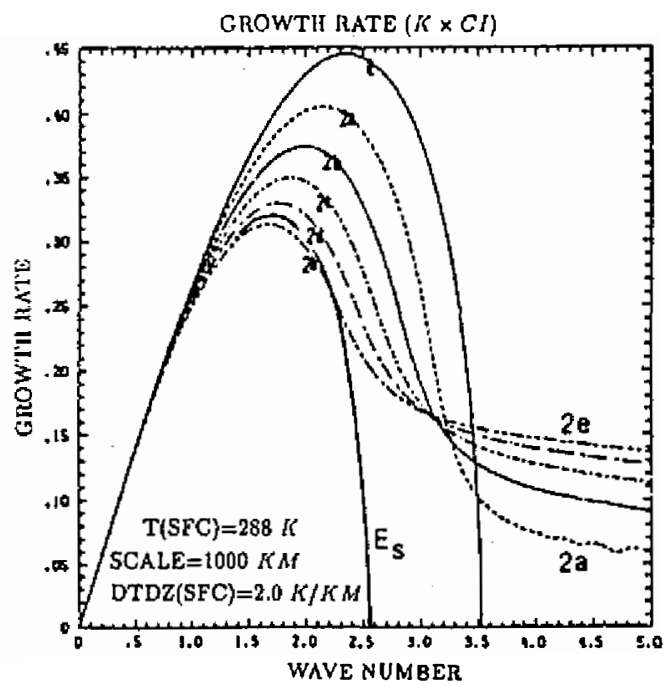

$F i g$. 4. Variations of the growth rate, $\alpha c_{i}$, with wave number. 
Table 1. Effects of stratification on the modified Eady model (Mode I).

$\begin{array}{lllllll}\text { case } & \begin{array}{l}\mathrm{d}^{2} \theta / \mathrm{dz}^{2} \\ \left(\mathrm{~K} \mathrm{~km}^{-2}\right)\end{array} & \begin{array}{c}\overline{\mathrm{d} \theta / \mathrm{dz}} \\ \left(\mathrm{K} \mathrm{km}^{-1}\right)\end{array} & \alpha_{\max } & \begin{array}{c}\lambda_{\max } \\ (\mathrm{km})\end{array} & \mathrm{c}_{\mathrm{r}, \max } & \alpha \mathrm{c}_{\mathrm{i}, \max } \\ \mathrm{E} & 0.0 & 2.0 & 2.360 & 2662 & 0.50 & .4453 \\ \mathrm{Es} & 0.0 & 3.9 & 1.69 & 3725 & 0.50 & .319 \\ 2 \mathrm{a} & .1 * 10^{-6} & 2.42 & 2.150 & 2922 . & 0.4951 & .4048 \\ 2 \mathrm{~b} & .2 * 10^{-6} & 2.84 & 1.990 & 3157 . & 0.4915 & .3741 \\ 2 \mathrm{c} & .3 * 10^{-6} & 3.27 & 1.865 & 3369 . & 0.4888 & .3497 \\ 2 \mathrm{~d} & .4 * 10^{-6} & 3.69 & 1.760 & 3570 . & 0.4867 & .3296 \\ 2 \mathrm{c} & .5 * 10^{-6} & 4.11 & 1.675 & 3751 . & 0.4848 & .3127\end{array}$

also shows that the most unstable wave length and growth rate of long waves with parabolic temperature profiles are quite comparable to the original Eady waves. However, the phase speed for the unstable waves for $2 \mathrm{a}-2 \mathrm{e}$ is no longer a constant value of 0.5 . It decreases slowly with increasing wave numbers in the Mode I region, and decreases more quickly in the Mode II region, as shown in Fig. 3. The transition wave numbers between Mode I and II also decrease from case $2 \mathrm{a}$ to $2 \mathrm{e}$. The phase speeds obtained here are similar to those obtained by Blumen and Nakamura, except that no neutral wave exists in our results, which is consistent with the critical layer instability (Bretherton, 1966a,b).

Fig. 3 also shows that the wavelength of the order of $4000 \mathrm{~km}$ will still dominate the spectrum of atmospheric fluctuation, while the mean basic static stability field is about the same as the standard atmosphere (i.e., $\partial \theta / \partial z \approx$ $3.5 \mathrm{~K} \mathrm{~km}^{-1}$ ). Fig. 4 reveals the shortwave cutoff for classical Eady waves, but short waves become unstable when the vertical variation of stratification is included (i.e, $\partial Q / \partial y \neq 0$ ), as expected. However, the growth rate of the short waves (Mode II) increases with increasing stratification aloft. The growth rate gradually decreases with increasing the wave number in Mode 2, but the decrease rate is very small for $2 \mathrm{e}$. The growth rate will be discussed further.

\section{STRUCTURE OF THE BAROCLINIC DISTURBANCES}

Figs. 5-6 show the nondimensional pressure and temperature perturbations $\left(\phi^{*}\right.$ and $\theta^{*}$ ) at wave number $\alpha_{1}=0.5 \times \pi$ (i.e, wavelength $=4000 \mathrm{~km}$ ) for case $2 \mathrm{a}$, which are very close to the conventional Eady waves, except that the perturbations are slightly weaker near the top than the bottom. Figs. 7-8 are for case $2 \mathrm{e}$, in which we can see that a stronger stratification aloft reduces the amplitude of $\theta^{*}$ in the upper layer considerably. This also reduces the height of the steering level so that the phase speed of $2 \mathrm{e}$ is smaller than that of $2 \mathrm{a}$, 
as discussed in Fig. 3. Overall, the fundamental structure of perturbations in Mode I remains similar to the original Eady waves. Those diagrams are also comparable to the long waves obtained by Nakamura (1988).

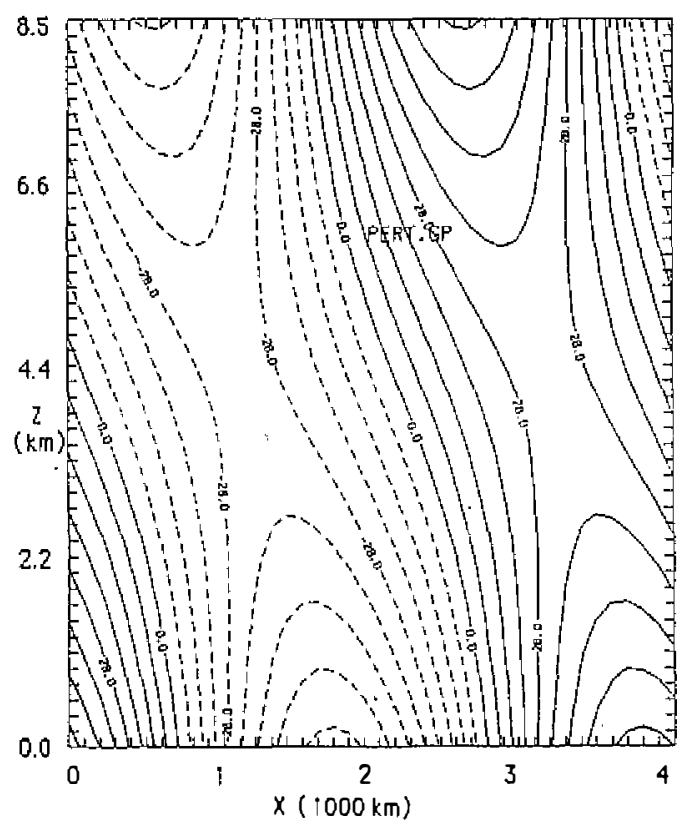

Fig. 5. Pressure perturbation $\phi^{*}$ for $2 a$ with wavelength $\lambda=4000 \mathrm{~km}$. The contour interval is 7.0.

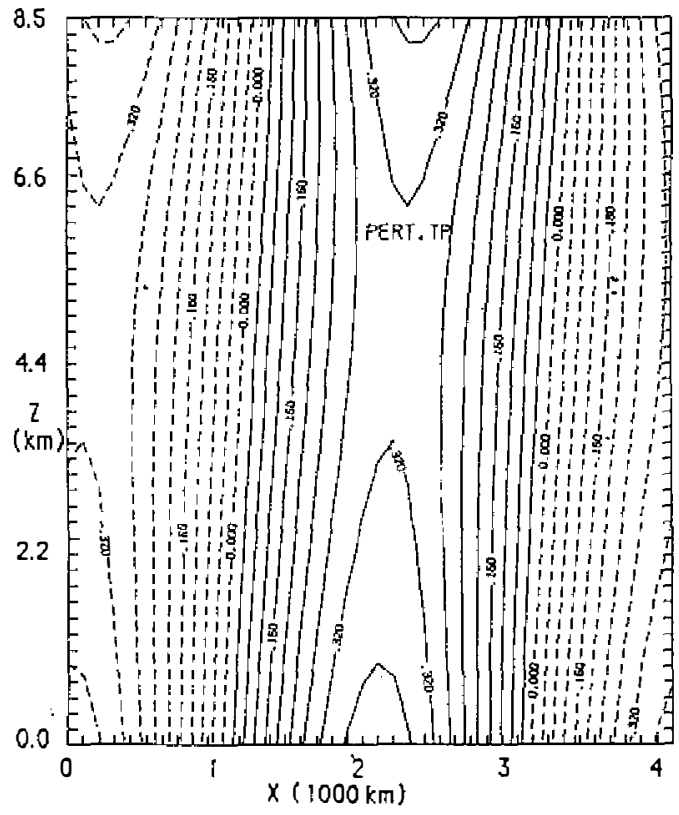

Fig. 6. Temperature perturbation $\theta^{*}$ for 2a with $\lambda=4000 \mathrm{~km}$. The contour interval is 0.04 .

The perturbations of $\phi^{*}$ and $\theta^{*}$ for wave number $\alpha_{2}=1.25 \times \pi$ (i.e., wavelength $=1600 \mathrm{~km}$ ) of Mode II are presented in Figs. 9-10 for 2a, and in Figs. 11-12 for 2e. The perturbations are more confined in the lower atmosphere, especially for case $2 \mathrm{e}$. The temperature field tilts slightly eastward in the lower layer, atop a transition layer, where it tilts westward drastically: The westward tilt of $\theta^{*}$ is very small above the transition layer. The structures of $\phi^{*}$ and $\theta^{*}$ for $2 \mathrm{e}$ are similar to the short waves discussed by Nakamura (1988). Bretherton $(1966 \mathrm{a}, \mathrm{b})$ argues that the presence of the new unstable modes can be caused by the existence of a gradient of the basic state potential vorticity (i.e, $\partial Q / \partial y \neq 0$ ) in the interior of the flow, according to E. (2.19). Stability of the short waves for a weak stratification in the lower atmosphere has also been studied by Staley and Gall (1977), Blumen (1979), and Kuo and Seitter (1985).

If we assume that the height of the disturbance can be measured by the height of the steering level, $h \approx c_{r} /(V / H)$. The $h_{2 a} \approx 3 \mathrm{~km}$ for $2 \mathrm{a}$, and $h_{2 e} \approx$ $2.5 \mathrm{~km}$ for $2 \mathrm{e}$. Those heights are comparable to the height of the transition 


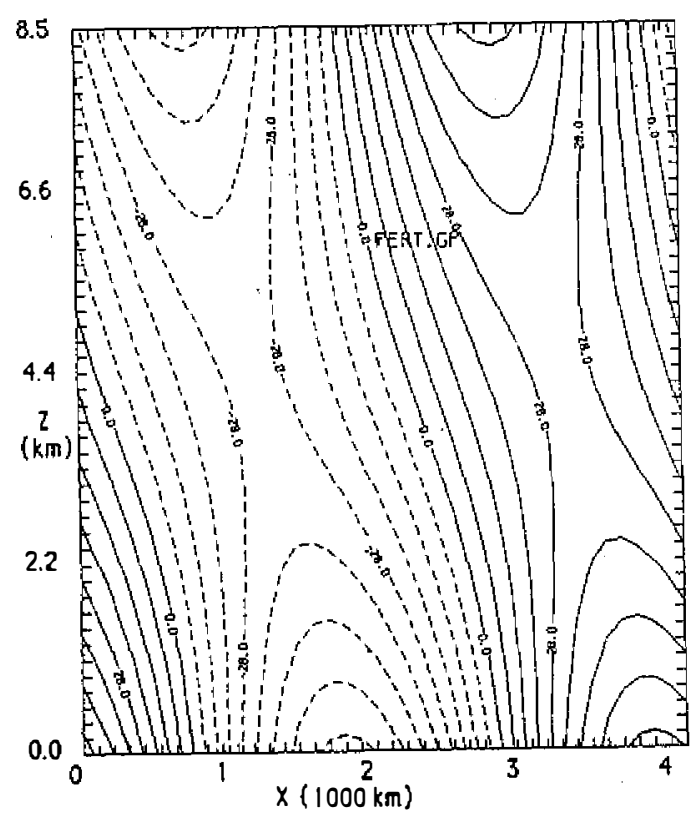

Fig. 7. Pressure perturbation $\phi^{*}$ for $2 \mathrm{e}$ with $\lambda=4000 \mathrm{~km}$. The contour interval is 7.0.

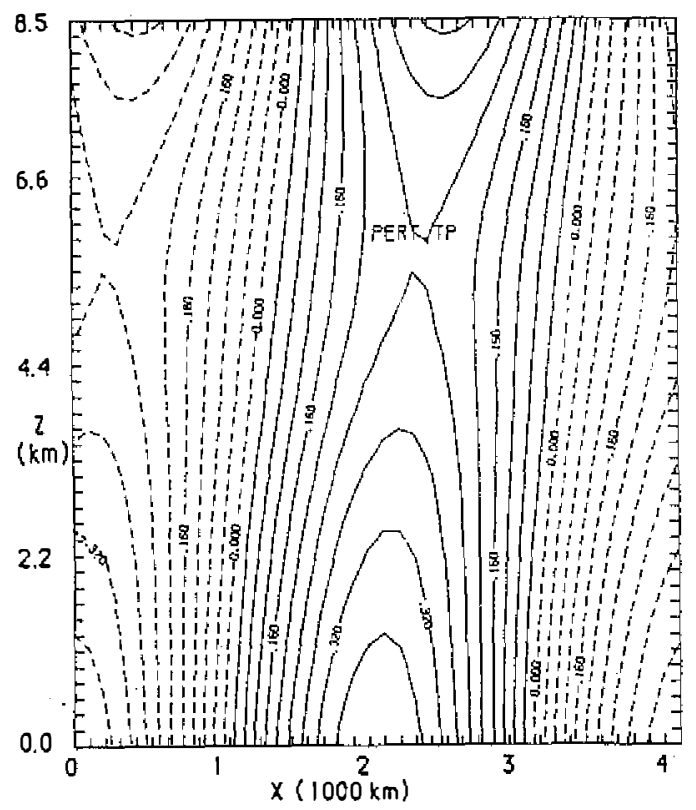

Fig. 8. Temperature perturbation $\theta^{*}$ for 2e with $\lambda=4000 \mathrm{~km}$. The contour interval is 0.04 .

level of $\theta^{*}$ shown in Figs. 10 and 12. $\partial \theta / \partial z=2.15 \mathrm{~K} \mathrm{~km}^{-1}$ at $z \approx 3 \mathrm{~km}$ for 2a; and $\partial \theta / \partial z=2.63 \mathrm{~K} \mathrm{~km}^{-1}$ at $z \approx 2.5 \mathrm{~km}$ for $2 \mathrm{e}$. The effective stratification of $2 \mathrm{a}$ is still much smaller than that of case 2e. However, for the short waves, the growth rate of $2 \mathrm{e}$ is larger, as shown in Fig. 4. Therefore, the short waves are sensitive to the stratification not only in the lower atmosphere but also in the upper layer, and to the height of the transition level. Comparing the perturbation fields of 2a (Figs. 9-10) and 2e (Figs. 11-12), we can see that the decrease of $\left|\phi^{*}\right|$ and $\left|\theta^{*}\right|$ with height in $2 \mathrm{a}$ is much slower, due to a weaker stable stratification aloft. Hence, there is no lid to prohibit the vertical motion from penetrating deeply into the upper stable layer. This situation is very similar to the penetrative convection discussed by Sun (1976), in which stability depends upon the Rayleigh number in the lower unstable layer, the stability number in the stable layer and the height of the interface. Hence, our growth rate of the short wave is different from the situation discussed by Blumen or Nakamura. They emphasize that the interface acts as a rigid lid to trap short waves in the lower layer due to a sharp change of $N^{2}$ in their models.

The (dimensional) kinetic energy ( $\mathrm{KE}$ ) equation can be expressed as

$$
\frac{d}{d t} \int \frac{1}{2}\left(u^{\prime 2}+v^{\prime 2}+w^{\prime 2}\right) d x d y d z=-\int u^{\prime} w^{\prime} \frac{d U}{d z} d x d y d z+\int \frac{g}{\theta_{0}} w^{\prime} \theta^{\prime} d x d y d z
$$




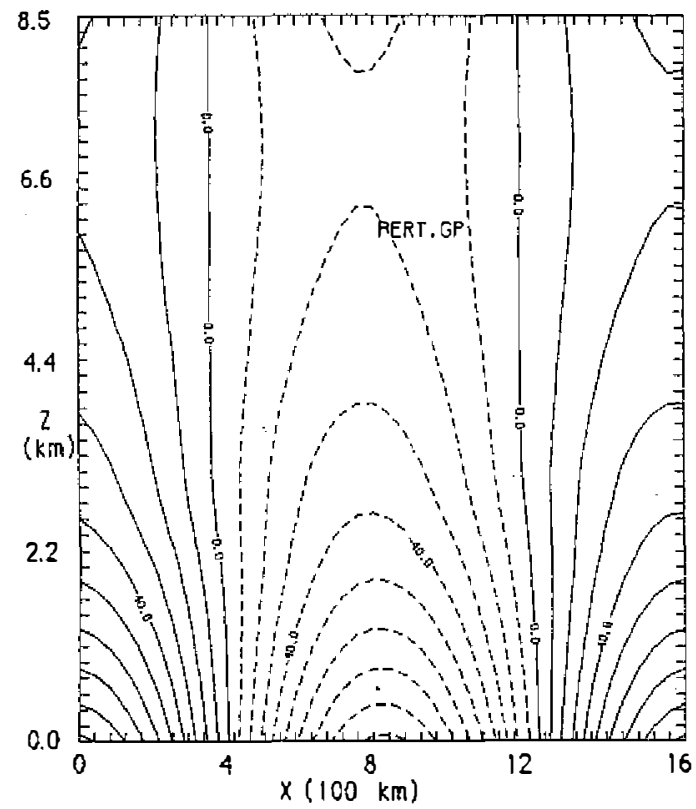

Fig. 9. $\phi^{*}$ for 2 a with $\lambda=1600 \mathrm{~km}$, the contour interval is $\mathbf{1 0}$.

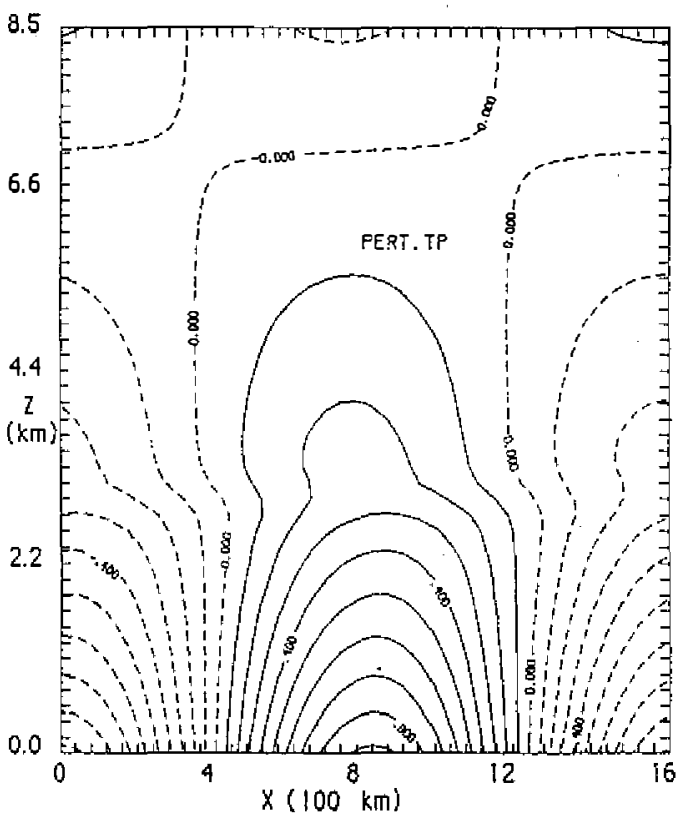

Fig. 10. $\theta^{*}$ for 2 a with $\lambda=1600 \mathrm{~km}$, the contour interval is 0.1 .

The shear production (A) is much smaller and negligible in comparison with the buoyancy production (B) in this study. The vertical distributions of the horizontal average of $\left(g / \theta_{0}\right) w^{\prime} \theta^{\prime}$ at $\lambda=1600 \mathrm{~km}$ for cases $2 \mathrm{a}$ and $2 \mathrm{e}$ shown in Fig. 13 reveal that the buoyancy production generated in $2 \mathrm{e}$ is much larger than in 2a for $z<h$. This is because a larger amplitude of perturbation is confined in the lower layer and because the phase angles of $w^{\prime}$ and $\theta^{\prime}$ are more in phase for $2 \mathrm{e}$. The buoyancy production decreases very rapidly near $z \approx h$ and becomes slightly negative for $z>h$. The value of buoyancy production in the entire domain, $B=0.0166$ in case $2 e$, is much larger than 0.0114 in case $2 \mathrm{a}$. On the other hand, $\mathrm{B}$ increases with height and reaches maximum at the mid-level in Eady wave, then gradually decays above. Similar profiles exist for long waves of $2 \mathrm{a}-2 \mathrm{e}$ in Mode I, except the height of the maximum $w^{\prime} \theta^{\prime}$ decreases with increasing of stratification aloft.

The total energy equation can be given as

$$
\begin{aligned}
\frac{d}{d t} \int \frac{1}{2}\left(u^{\prime 2}+v^{\prime 2}+w^{\prime 2}+\frac{g \theta^{\prime 2}}{d \theta / d z}\right) d x d y d z= & -\int u^{\prime} w^{\prime} \frac{d U}{d z} d x d y d z \quad \text { A } \\
& -\int \frac{g}{\theta_{0}} v^{\prime} \theta^{\prime} \frac{\partial \theta / \partial y}{\partial \theta / \partial z} d x d y d z
\end{aligned}
$$

The vertical distributions of the horizontal averages of $(\mathrm{C})$ in (4.2) for $2 \mathrm{a}$ and 2e at $\lambda=1600 \mathrm{~km}$ are also shown in Fig. 13. The energy conversion in the 


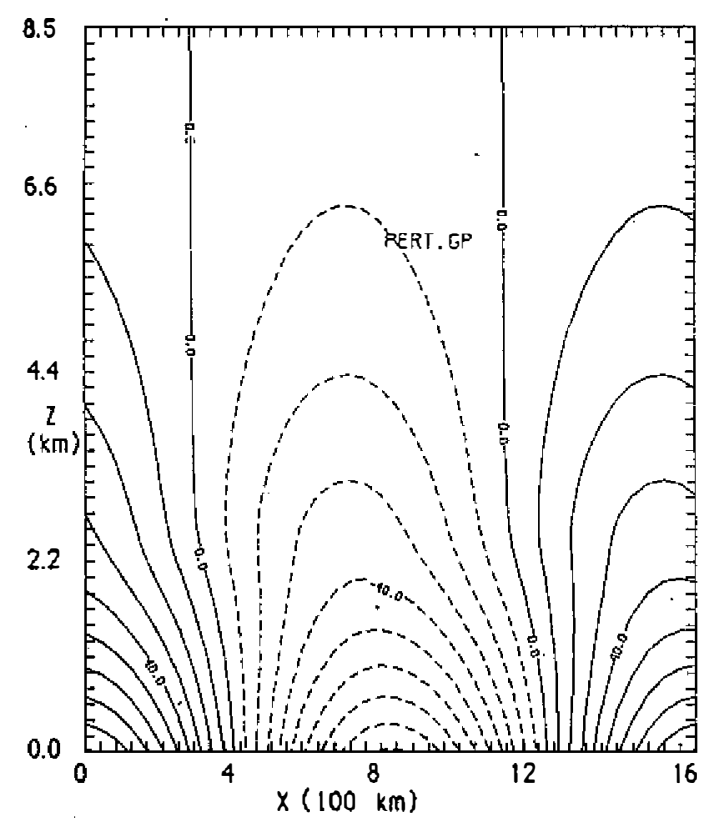

Fig. 11. $\phi^{*}$ for $2 e$ with $\lambda=1600 \mathrm{~km}$, the contour interval is 10 .

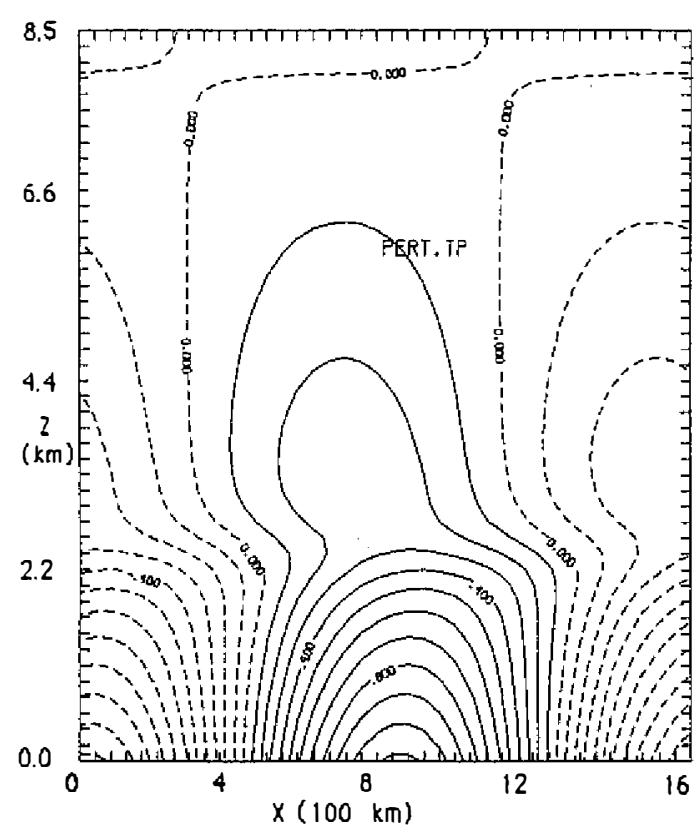

Fig. 12. $\theta^{*}$ for $2 \mathrm{e}$ with wavelength $\lambda=$ $1600 \mathrm{~km}$, the contour interval is 0.1 .

entire domain, $C=0.039$ in $2 \mathrm{e}$ is also much larger than $C=0.021$ in $2 \mathrm{a}$, which may explain why the short wave of $2 \mathrm{e}$ is more unstable than 2a. The energy conversions of the entire domain are also presented in Tables 2 and 3 . It is noted that the comparative value instead of the absolute value of each one is important. It is also noted that the values of Table 2 should not be compared with those in Table 3. We may define the effective Burger number as

$$
\beta \mathrm{eff}=\frac{g\left(2 h^{*}\right)^{2}}{\theta_{0} f^{2} \lambda^{2}}\left(\frac{\partial \theta}{\partial z}\right)_{z=h^{*}}
$$

where $h^{*}$ is the height of the maximum horizontal average $w^{\prime} \theta^{\prime}$, and $\lambda$ is wavelength. The height of $h^{*}$ is slightly less than $h\left(\approx H \times c_{r} / V\right)$ and the decrease of buoyancy production above $h^{*}$ is drastic, which indicates that the generation of the kinetic energy mainly comes from the lower portion of circulation. The values of variables in (4.3) for short waves are shown in Tables 4 . With $\lambda=1600 \mathrm{~km}$, we obtain that $\beta$ eff $(2 \mathrm{a})=0.072$ for $2 \mathrm{a}$ and $\beta \mathrm{eff}(2 \mathrm{e})=0.047$ for $2 \mathrm{e}$, which may also explain a larger growth rate of the short wave $(\lambda=1600 \mathrm{~km})$ for case 2e. When (4.2) is applied for the long wave $(\lambda=4000 \mathrm{~km}$ and $2 h^{*} \approx 6.68 \mathrm{~km}, \partial \theta / \partial z \approx 3.67 \mathrm{~K} \mathrm{~km}^{-1}$ ) for case $2 \mathrm{e}$, we obtain $\beta$ eff $=0.035$, which is still less than 0.047 of the short wave at $\lambda=1600 \mathrm{~km}$. This may suggest that the effective Burger number may be a better parameter than the 


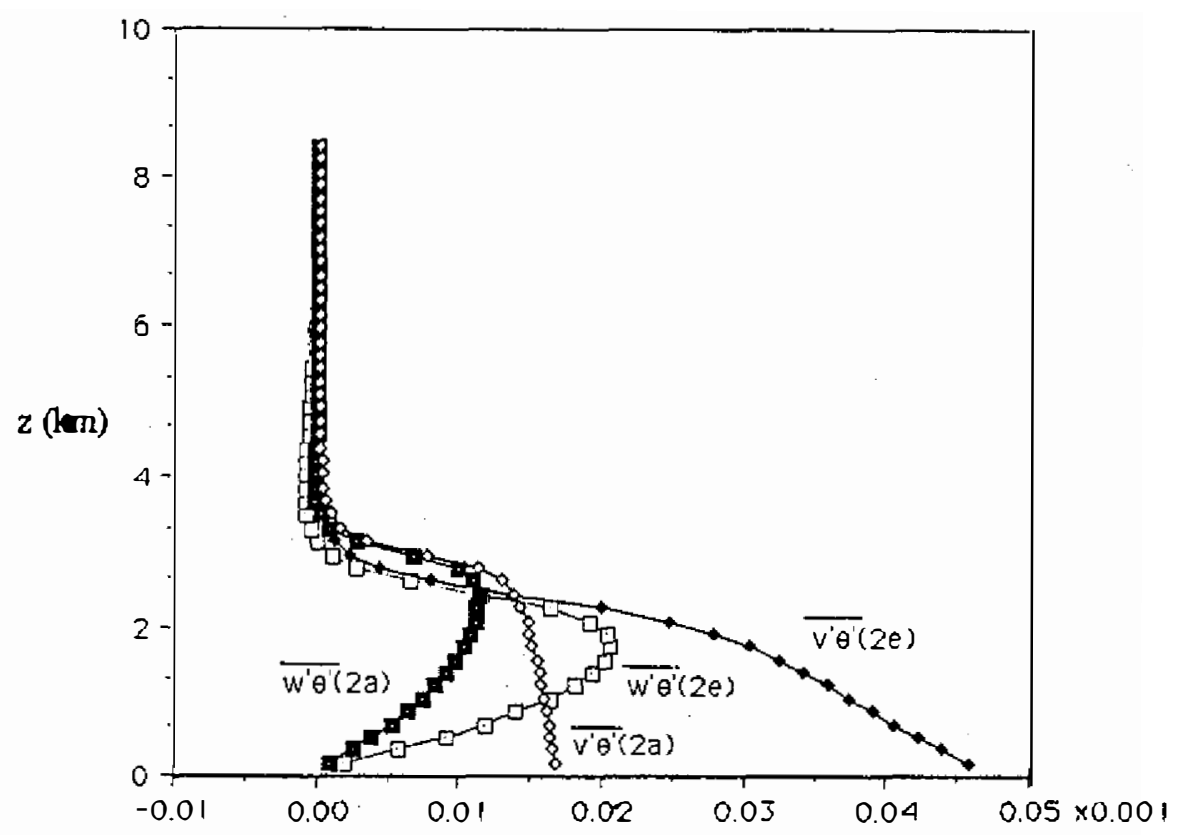

Fig. 13. Horizontal average of energy conversions $w^{\prime} \theta^{\prime}$ and $v^{\prime} \theta^{\prime}$ for $2 \mathrm{a}$ and $2 \mathrm{e}$.

Table 2. The energy conversions of Eqs. (4.1)-(4.2) in the entire domain at $\lambda=4000 \mathrm{~km}$.

$\begin{array}{lllllll} & \mathrm{E} & 2 \mathrm{a} & 2 \mathrm{~b} & 2 \mathrm{c} & 2 \mathrm{~d} & 2 \mathrm{e} \\ \text { (A) } & -0.112 * 10^{-3} & -0.104 * 10^{-3} & -0.980^{*} 10^{-4} & -0.913 * 10^{-4} & -0.849 * 10^{-4} & -0.786^{*} 10^{-4} \\ \text { (B) } & 0.892 * 10^{-2} & 0.841 * 10^{-2} & 0.791 * 10^{-2} & 0.742 * 10^{-2} & 0.694 * 10^{-2} & 0.648 * 10^{-2} \\ \text { (C) } & 0.502 * 10^{-1} & 0.402 * 10^{-1} & 0.334 * 10^{-1} & 0.285 * 10^{-1} & 0.248 * 10^{-1} & 0.218 * 10^{-1}\end{array}$

Table 3. The energy conversions of Eqs. (4.1)-(4.2) in the entire domain at $\lambda=1600 \mathrm{~km}$.

$\begin{array}{cccccc} & 2 \mathrm{a} & 2 \mathrm{~b} & 2 \mathrm{c} & 2 \mathrm{~d} & 2 \mathrm{e} \\ \text { (A) } & -0.558^{*} 10^{-3} & -0.646 * 10^{-3} & -0.637 * 10^{-3} & -0.602 * 10^{-3} & -0.562 * 10^{-3} \\ \text { (B) } & 0.114^{*} 10^{-1} & 0.147 * 10^{-1} & 0.161 * 10^{-1} & 0.165 * 10^{-1} & 0.166^{*} 10^{-1} \\ \text { (C) } & 0.213 * 10^{-1} & 0.300 * 10^{-1} & 0.347 * 10^{-1} & 0.374 * 10^{-1} & 0.391 * 10^{-1}\end{array}$

effective stratification in order to determine instability of baroclinic waves for the cases discussed here, although the growth rate is also a function of other 

$\mathrm{km}$.

Table 4. The values of $h^{*}, \partial \theta / \partial z$ at $z=h^{*}$, and $\beta$ etf of Eq. (4.3) at $\lambda=1600$

$\begin{array}{llllll} & 2 \mathrm{a} & 2 \mathrm{~b} & 2 \mathrm{c} & 2 \mathrm{~d} & 2 \mathrm{c} \\ \mathrm{h}^{*}(\mathrm{~km}) & 2.46 & 2.10 & 2.02 & 1.93 & 1.75 \\ \partial \theta / \partial \mathrm{z}(\mathrm{K} / \mathrm{km}) & 2.24 & 2.42 & 2.60 & 2.77 & 2.87 \\ \text { Beff } & 0.072 & 0.057 & 0.056 & 0.055 & 0.047\end{array}$

parameters, such as $(f \partial U / \partial z) /(\partial \theta / \partial z)$ and others.

By using the two-dimensional version of the Purdue mesoscale model (Sun and $\mathrm{Hsu}, 1988$ ), we have found that both long waves and short waves obtained in this linear stability analysis are also unstable in a nonlinear system, which will be presented in Part II. Numerical simulations obtained by Orlanski (1986) also show that the short waves can develop in the lower atmosphere with a weak stratification.

\section{SUMMARY AND REMARKS}

Two different types of disturbances can be generated by baroclinicity with parabolic temperature profiles in the vertical direction. The waves are unstable in all the test wave numbers. The longwave disturbances in the Mode I region are quite similar to the classical Eady problem, which has a larger growth rate and propagates faster than short waves in the Mode II region. The shortwave disturbances are mainly confined to the lower atmosphere, where the stratification is weaker. The growth rate of the short waves decreases with increased stratification aloft. Although the long waves are more unstable than the short waves, according to linear stability in a quasigeostrophic system, the short waves may become dominant through nonlinear interactions, and/or enhanced by diabatic heating in the lower atmosphere, which remain to be investigated. The short waves generated here may be associated with the medium-scale disturbances observed over the AMTEX region, or the surface front in the lower atmosphere with a weak stratification.

Acknowledgements. Contributions of Ms. R. L. Kao and Mr. A. Yildirim on this work are appreciated. Part of this work was supported by NSF under grant ATMS-8611729 and ATM-8907881.

\section{REFERENCES}

Blumen, W., 1979: On short-wave baroclinic instability. J. Atmos. Sci., 36, 
1925-1933.

Bretherton, F. P., 1966a: Critical layer instability in baroclinic flows. Quart. J. Roy. Meteor. Sco., 92., 335-345.

Bretherten, F. P., 1966b: Baroclinic instability and the short wavelength cut-off in terms of potential vorticity. Quart. J. Roy. Meteor. Soc., 92, 335-345. Charney, J. G., and M. E. Stern, 1962: On the stability of internal baroclinic jets in a rotating atmosphere., J. Atmos. Sci., 19, 159-163.

Drazin, P. G., 1978: Variations on a theme of Eady Wave. on "Rotational Fluids in Geophysics" - Academic Press Inc., New York, U.S.A., pp. 139169.

Eady, E. T., 1949: Long waves and cyclone waves. Tellus, 1, 33-52.

Gamb•, K., 1970a: The characteristic feature of medium-scale disturbances in the atmosphere I. J. Meteor. Soc. Japan, 48, 173-184.

Gambo, K., 1970b: The characteristic feature of medium-scale disturbances in the atmosphere II. J. Meteor. Soc. Japan, 48, 315-330.

Hoskins, B. J., 1971: Atmospheric frontogenesis: some solutions. Quart. J. Roy. Meteor. Soc., 97, 139-153.

Hoskins, B. J., 1978: Baroclinic Instability and Frontogensis in Rotating Fluids in Geophysics., P. H. Roberts, ed., Academic Press. 171-204.

Kao, R. L., 1987: Baroclinic instability and frontogenesis. M. S. Thesis, Department of Earth and Atmospheric Sciences, Purdue University, W. Laf., IN., 109pp.

Kuo, H. L., 1978: A two-layer study of the combined barotropic and baroclinic instability in the tropics. J. Atmos. S.ci., 35, 1840-1860.

Iruo, H. L, and IK. L. Seitter, 1985: Instability of shearing geostrophic currents in neutral and partly unstable atmosphere. J. Atmos. Sci., 42, 331-345.

Nakamura, N., 1988: Scale selection of baroclinic instability- effects of stratification and nongeostrophy: J. Atmos. Sci., 45, 3253-3267.

Nitta, T., and M., Nanbu and M. Yoshizali, 1973: Wave disturbances over the China Continent and the Eastern China Sea in February 1968, J. Meteor. Soc. Japan, 51, 11-28.

Orlanski, I., 1986: Localized baroclinicity: A source for mesoscale-a cyclones. J. Atmos. Sci., 43, 2857-285.

Staley, D. O., and R. L. Gall, 1977: On the wavelength of maximum baroclinic instability. J. Atmos. Sci., 34, 1679-1688.

Stone, P. H., 1966: On non-geostrophic baroclinic stability. J. Atm $\bullet$ sci., 23, 38-52.

Sun, W. Y., 1976: Linear stability of penetrative convection. J. Atmos. Sci., 33, 1911-1920.

Sun, W. Y., ancl W. R. Hsu, 1988: Numerical study of cold air outbreak over the warm ocean. J. Atmos Sci., 45, 1205-1227. 
Sun, W. Y., 1989: Modified Eady Waves and Frontogenesis. Part II: Nonlinear Integration. TAO, 1, 379-391.

Tokioka, T., 1970: Non-geostrophic and non-hydrostatic stability of a baroclinic fluid. J. Meteor. Soc. Japan, 48, 503-520.

Tokioka, T., 1971: Supplement to non-geostrophic and non-hydrostatic instability of a baroclinic fluid and medium-scale disturbances on the fronts. J. Meteor. Soc. Japan, 49, 129-132.

Williams, G. P., 1974: Generalized Eady waves. J. Fluid. Mech., 62, 643-655. Williams, R. T., 1967: Atmospheric frontogenesis: A numerical experiment. $J$. Atmos. Sci., 24, 627-641. 


\title{
改造之Eady波與鋒生 \\ 第一部分 線性穩定性之分析
}

\author{
颜女䣡 \\ 美國普渡大學地球和大雨利學系
}

\section{摘 要}

斜壓不稳定性在一非秥滞性且位溫剖面爲拖物線型之流體中將被研討。在上遮狀況下， 並無短波割離産生, 此與傳統的Eady模式不同。除了長波摄動（與Eady波相似）之外，短波 㩲動亦可在成層較弱的低勫中發展。短波之成長率會隨著成層隨高度增加而增加。從結果中 顯示短波摄動可以穿透至高層的稳定層。這些波之成長率與按動可能與有妍的Burger數目有 關, Burger數定義爲

$$
\text { Beff }=\frac{g\left(2 h^{*}\right)^{2}}{\theta_{0} f^{2} \lambda^{2}} \frac{2 \theta}{2 z} h^{*}
$$

其中h*第垂直熱通量 $\left(W^{\prime} \theta^{\prime}\right)$ 最大處之高度而 $\lambda$ 是水平的波長。

由本文第二部分中經由非線性中尺度模式之數值模擬中亦證實了短波在短短幾天內可以 發展成一地面鋒, 而這些短波可能就是對應於AMTEX實驗中所觀測到的中尺度授動。 